\title{
Human $\beta$-defensin-2 induction in Helicobacter pylori-infected gastric mucosal tissues: antimicrobial effect of overexpression
}

\author{
N. Uehara, ${ }^{1}$ A. Yagihashi, ${ }^{2}$ K. Kondoh, ${ }^{1}$ N. Tsuji, ${ }^{2}$ T. Fujita, ${ }^{3}$ H. Hamada ${ }^{4}$ and \\ N. Watanabe ${ }^{2}$
}

Correspondence

N. Watanabe

watanabn@sapmed.ac.jp

Received 6 June 2002

Accepted 20 September 2002
Division of Laboratory Diagnosis ${ }^{1}$ and Departments of Clinical Laboratory Medicine ${ }^{2}$, Plastic and Reconstructive Surgery ${ }^{3}$ and Molecular Medicine ${ }^{4}$, Sapporo Medical University School of Medicine, South-1, West-16, Chuo-ko, Sapporo 060-8543, Japan

\section{INTRODUCTION}

Defensins are antimicrobial peptide components of the innate immune system against micro-organisms. Two subfamilies, $\alpha$ - and $\beta$-defensins, distinguished according to structural features at the gene and protein levels, have been identified in vertebrates (Diamond \& Bevins, 1998). Three $\beta$ defensins were recently characterized in various human epithelial cells. Human $\beta$-defensin (hBD)-1 mRNA is expressed constitutively in various epithelial tissues (Harder $e t$ al., 1997). hBD-2 mRNA expression is detected in epithelial cells of the skin, lung, trachea and urogenital tract and can be induced by treatment with tumour necrosis factor (TNF)- $\alpha$ or interleukin (IL)-1 or by exposure to micro-organisms (Wada et al., 1999, 2001; Hamanaka et al., 2001; O'Neil et al., 2000). Both hBD-1 and hBD-2 show antimicrobial activity, predominantly against Gram-negative bacteria. hBD-3 mRNA, expressed in the skin, tonsil and trachea, can be induced in epithelial cells by treatment with TNF- $\alpha$ or contact with Pseudomonas aeruginosa and shows antimicrobial activity against Gram-negative and Gram-positive bacteria (Harder et al., 2001).

Recently, induction of hBD-2 mRNA expression by Helicobacter pylori has been shown in human gastric cancer cell lines (MKN45 and AGS) (Wada et al., 1999, 2001; Hamanaka

Abbreviation: hBD-2, human $\beta$-defensin-2. et al., 2001; O'Neil et al., 2000). Gastric colonization by $H$. pylori, which is Gram-negative, is pathogenetically important in gastritis, peptic ulcer, gastric cancer and gastric mucosaassociated lymphoid tissue lymphoma. However, hBD-2 mRNA expression in gastric mucosal tissues has not been fully characterized.

To understand the innate immune response to $H$. pylori, we determined hBD-2 expression in various gastric mucosal tissues with or without $H$. pylori infection using a semiquantitative TaqMan RT-PCR assay as well as immunohistochemistry. Additionally, the antimicrobial effect of hBD-2 against $H$. pylori was evaluated in transfection experiments.

\section{METHODS}

Bacterial strains. H. pylori ATCC $43504^{\mathrm{T}}$, Salmonella typhimurium ATCC 14028, Escherichia coli ATCC 25922, Staphylococcus aureus ATCC 25923 and Enterococcus faecalis ATCC 33186 were used for hBD-2 mRNA induction.

hBD-2 mRNA induction in MKN45 gastric cancer cells. MKN45 gastric cancer cells were cultured in RPMI 1640 medium (BioWhittaker) supplemented with heat-inactivated fetal bovine serum (FBS) (JRH Biosciences) at $37^{\circ} \mathrm{C}$ in an atmosphere including $5 \% \mathrm{CO}_{2}$. Induction of hBD-2 mRNA was carried out as described by Wada et al. (1999). Briefly, $10^{6}$ MKN45 cells were seeded into dishes $60 \mathrm{~mm}$ in diameter and incubated for $12 \mathrm{~h}$. Culture medium was replaced with $2 \mathrm{ml}$ fresh RPMI 1640 medium without FBS. Bacterial suspensions 
( $100 \mu \mathrm{l} ; 0-10^{8}$ c.f.u. $\mathrm{ml}^{-1}$ in RPMI 1640 medium) were added to the dishes and incubation was continued for various periods of time.

Tissue samples. Samples of primary tumour, mucosa showing intestinal metaplasia, mucosa with chronic gastritis and normal mucosa were obtained from seven patients with previously untreated gastric cancer following surgery at Sapporo Medical University Hospital. Informed consent was obtained from all patients. After tissue removal, all samples were frozen immediately and fixed in $10 \%$ formalin. All histological factors were evaluated according to the criteria of the Japanese Research Society for Gastric Cancer (1995).

Determination of $\boldsymbol{H}$. pylori infection. Sections were Giemsa-stained and the rapid urease test (CLO test; Tri-Med Specialties Inc.) was performed with fresh samples from the prepyloric antrum, greater curvature of the corpus and fundus (Marshall et al., 1987). H. pylori infection was defined as positive when $H$. pylori was detected and/or the CLO test was positive.

Quantitative RT-PCR assay for hBD-2 mRNA. ISOGEN (Nippon Gene) was used to extract total RNA from cells or tissues and this extract was assayed for RNA with the Gene Quant DNA/RNA calculator (Amersham Pharmacia Biotech). For quantitative RT-PCR, fluorescent hybridization probes and the TaqMan PCR core reagents kit with AmpliTaq Gold (Perkin-Elmer Applied Biosystems) were used with the ABI Prism 7700 sequence detection system (Perkin-Elmer Applied Biosystems). Expression of hBD-2 mRNA was quantified by methods reported previously (Yajima et al., 1998). Primers and the TaqMan probe for hBD-2 mRNA were as follows: forward primer, $5^{\prime}$-ATC CAGTCTTTTGCCCTAGAAGGTA-3'; reverse primer, 5'-GGCTTT TTGCAGCATTTTGTTC-3'; TaqMan probe, $5^{\prime}$-AAACAAATTGGC ACCTGTGGTCTCCCT- $3^{\prime}$. Aliquots of $25 \mathrm{ng}$ total RNA from samples were used for one-step RT-PCR. Conditions of one-step RT-PCR were as follows: $30 \mathrm{~min}$ at $48{ }^{\circ} \mathrm{C}$ (stage 1, reverse transcription), $10 \mathrm{~min}$ at $95^{\circ} \mathrm{C}$ (stage 2, RT inactivation and AmpliTaq Gold activation) and then 40 cycles of amplification for $15 \mathrm{~s}$ at $95^{\circ} \mathrm{C}$ and $1 \mathrm{~min}$ at $60{ }^{\circ} \mathrm{C}$ (stage 3 , PCR). Data for hBD-2 mRNA were normalized to data for glyceraldehyde-3-phosphate dehydrogenase.

Immunostaining. Formalin-fixed, paraffin-embedded tissue sections were stained with polyclonal goat antibody against hBD-2 (Santa Cruz Biotechnology) or non-immune goat serum using an indirect immunoperoxidase technique.

Vector construction and generation of hBD-2-producing cells. The full-length hBD-2 gene was amplified by RT-PCR using hBD-2specific primers (forward primer, 5'-CGGGATCCATGAGGGTCTTG TATCTCCTCTTCTC-3'; reverse primer, 5' -CGGAATTCGGATCCT CATGGCTTTTTGCAGCATTTT GTTC-3'). Total cellular RNA was extracted from the human oral cancer cell line HSC2 as a template. The amplified product was digested with Bam HI and inserted at the BglII site of vector pCAcc (Yoshida \& Hamada, 1997). The sequence and orientation of the hBD-2 gene in the vector were confirmed by sequencing. This construct was designated pCAhBD-2. Briefly, 3T3J2 cells were co-transfected with pCAhBD-2 and a plasmid containing a neomycin-resistance gene using LipofectAmine (Gibco-BRL) according to the manufacturer's instructions. After selection with G418 $\left(500 \mu \mathrm{g} \mathrm{ml}^{-1}\right.$; Gibco-BRL), hBD-2 gene-transfected cells were cloned by a limiting-dilution method.

Antimicrobial assay. To evaluate the antimicrobial effect of hBD-2 on H. pylori, $25 \mu \mathrm{l}$ of a suspension of $4 \times 10^{6}$ c.f.u. H. pylori strain ATCC $43504^{\mathrm{T}} \mathrm{ml}^{-1}$ was cultured on HP agar (Eikenkagaku) after a 1-4 h preincubation at $37^{\circ} \mathrm{C}$ in the presence or absence of culture supernatant obtained from hBD-2-3T3J2-1 cells. To determine the number of c.f.u., the pre-incubation mixture was diluted 100 -fold immediately with culture medium and samples were cultured in triplicate. Viable cells (c.f.u. $\mathrm{ml}^{-1}$ ) were counted after 3 days in culture at $37^{\circ} \mathrm{C}$.

\section{RESULTS AND DISCUSSION}

\section{Induction of hBD-2 mRNA expression in MKN45 cells and expression of hBD-2 in various gastric mucosal tissues}

To clarify the effect of $H$. pylori on hBD-2 mRNA expression by using TaqMan RT-PCR, MKN45 cells were first incubated for 1-20 h with $H$. pylori. hBD-2 mRNA expression was detected in MKN45 cells $1 \mathrm{~h}$ after starting incubation with H. pylori and reached a maximum at $10 \mathrm{~h}$ (Fig. 1).

To determine a suitable number of $H$. pylori bacteria for induction of hBD-2 mRNA expression, $100 \mu \mathrm{l}$ aliquots of suspensions containing $0-10^{8}$ c.f.u. H. pylori $\mathrm{ml}^{-1}$ were incubated with MKN45 cells for $7 \cdot 5 \mathrm{~h}$. hBD-2 mRNA expression was up-regulated in a manner dependent on numbers of bacteria (Fig. 2), being first detectable at $10^{4}$ c.f.u. $\mathrm{ml}^{-1}$.

To determine whether other species of bacteria could induce hBD-2 mRNA expression in MKN45 cells, the cells were exposed to Salmonella typhimurium, Escherichia coli, Staphylococcus aureus or Enterococcus faecalis for $7 \cdot 5 \mathrm{~h}$. hBD-2 mRNA expression in MKN45 cells was induced by all species of bacteria assessed in this study (Fig. 3). Gram-negative bacteria were more effective than Gram-positive bacteria in inducing hBD-2 mRNA expression in MKN45 cells (Fig. 3).

To evaluate the effect of $H$. pylori colonization in gastric tissues on hBD-2 expression, gastric cancer and paired adjacent mucosa showing gastritis from four $H$. pyloripositive and three $H$. pylori-negative patients were assessed by TaqMan RT-PCR analysis and immunostaining. In $H$. pylori-positive specimens, the mean expression of $\mathrm{hBD}-2$

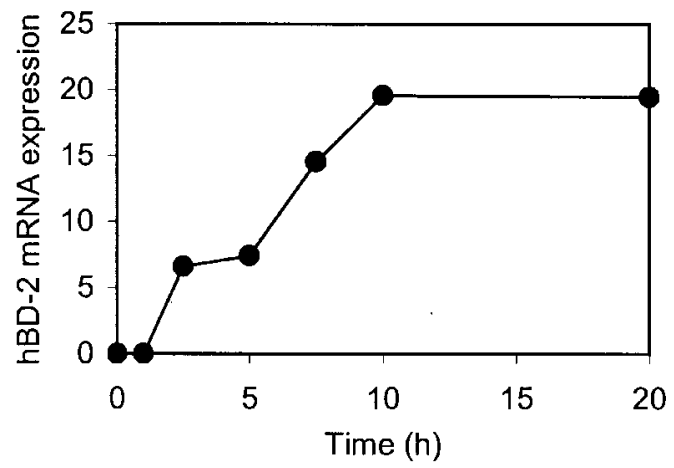

Fig. 1. Time-course of hBD-2 mRNA expression induced by $H$. pylori in a gastric cancer cell line. MKN45 cells $\left(10^{6}\right)$ were seeded into dishes $60 \mathrm{~mm}$ in diameter and incubated for $12 \mathrm{~h}$. Culture medium was replaced with $2 \mathrm{ml}$ fresh RPMI 1640 medium without FBS. The cells were incubated for $1-20 \mathrm{~h}$ with $100 \mu \mathrm{l}$ of a suspension of $10^{8}$ c.f.u. H. pylori ml ${ }^{-1}$. hBD-2 mRNA expression was measured by TaqMan RT-PCR. 


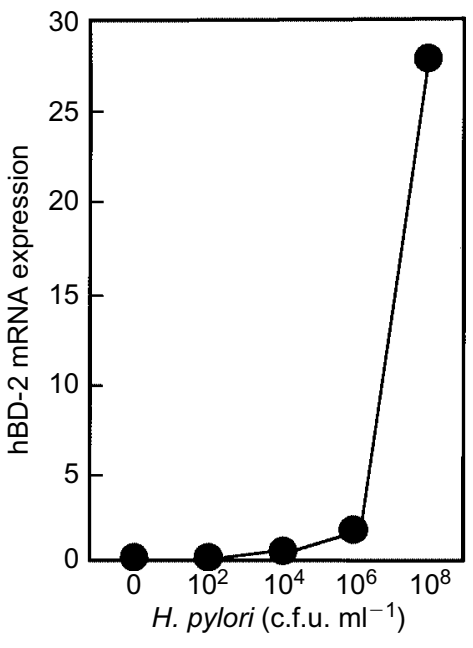

Fig. 2. Induction of hBD-2 mRNA expression by various numbers of H. pylori cells. MKN45 cells $\left(10^{6}\right)$ were seeded into dishes $60 \mathrm{~mm}$ in diameter and incubated for $12 \mathrm{~h}$. Culture medium was replaced with $2 \mathrm{ml}$ fresh RPMI 1640 medium without FBS. Bacterial suspensions (100 $\mu$ l; 0-10 $0^{8}$ c.f.u. $\mathrm{ml}^{-1}$ in RPMl 1640 medium) were added to the dishes and incubation was continued for 7.5 h. hBD-2 mRNA expression was measured by TaqMan RT-PCR.

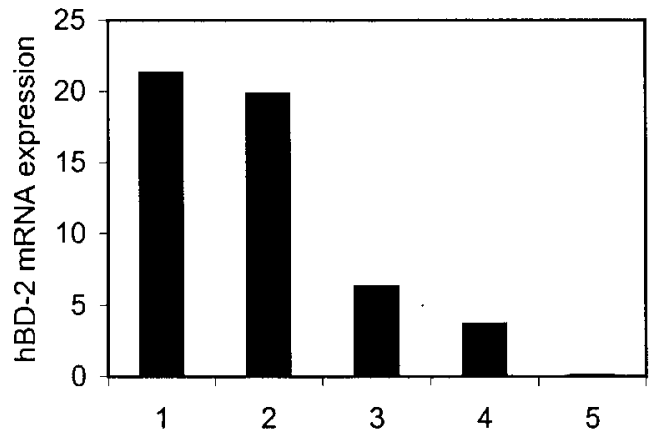

Fig. 3. Induction of hBD-2 mRNA expression by various bacterial species. MKN45 cells $\left(10^{6}\right)$ were seeded into dishes $60 \mathrm{~mm}$ in diameter and incubated for $12 \mathrm{~h}$. Culture medium was replaced with $2 \mathrm{ml}$ fresh RPMI 1640 medium without FBS. The cells were exposed for $7.5 \mathrm{~h}$ to $100 \mu \mathrm{l}$ of a suspension containing $10^{8}$ c.f.u. $\mathrm{ml}^{-1}$ of $\mathrm{H}$. pylori (1), Salmonella typhimurium (2), Escherichia coli (3), Staphylococcus aureus (4) or Enterococcus faecalis (5). hBD-2 mRNA expression was measured by TaqMan RT-PCR.

mRNA was $26 \cdot 5$ (Fig. 4 ). In contrast, the mean expression of hBD-2 mRNA in $H$. pylori-negative specimens was $0 \cdot 27$ (Fig. 4). The difference was significant $(P=0.028$; MannWhitney U test).

hBD-2 protein was detected in gastric cancers and paired adjacent non-neoplastic tissue showing gastritis from $H$. pylori-positive patients, but not in specimens from two of three H. pylori-negative patients (Fig. 5).

Using TaqMan RT-PCR for hBD-2 mRNA and immunos-

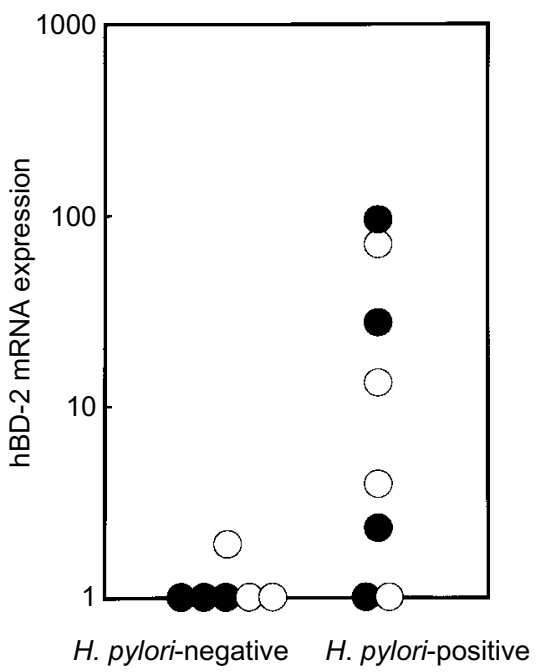

Fig. 4. hBD-2 mRNA expression in gastric cancers (o) and paired specimens of adjacent mucosa showing gastritis (•) from four $\mathrm{H}$. pylori-positive and three $\mathrm{H}$. pylori-negative patients.

taining for hBD-2 protein, we demonstrated that hBD-2 is expressed in gastric mucosa with $H$. pylori infection showing gastritis, but not in inflamed mucosa without $H$. pylori infection. In addition, hBD-2 mRNA expression was detected in gastric cancers from patients with $H$. pylori infection and hBD-2 mRNA expression was induced in the MKN45 gastric cancer cell line according to the intensity of $H$. pylori exposure. However, the level of expression of hBD-2 mRNA was variable in inflamed gastric mucosa and in cancers. A recent report has indicated that IL- 1 and TNF- $\alpha$ can induce hBD-2 mRNA expression and that $H$. pylori, but not culture filtrate, increased hBD-2 mRNA expression in MKN45 cells (Wada et al., 1999). These results imply that contact of gastric epithelial cells with $H$. pylori and the amounts of proinflammatory cytokines are important in induction of $\mathrm{hBD}$ mRNA expression. In addition, the magnitude of gastritis was variable in our cases. Our results might reflect the number of $H$. pylori cells in the gastric mucosa or influences of other factors such as proinflammatory cytokines.

Isomoto et al. (2000) detected activated NF- $\kappa \mathrm{B}$ in epithelial cells in gastric mucosa of patients with $H$. pylori-associated gastritis. Recent reports suggest that only $H$. pylori strains (type I) that carry a cag pathogenicity island (PAI) induce activation at the NF- $\kappa \mathrm{B}$ site of the hBD-2 promoter (Wada et al., 1999, 2001). In the present study, all clinical H. pylori isolates from four patients with $H$. pylori infection had a cag A (data not shown), and as did H. pylori ATCC $43504^{\mathrm{T}}$. Moreover, exposure of MKN45 cells to Salmonella typhimurium ATCC 14028, Escherichia coli ATCC 25922, Staphylococcus aureus ATCC 25923 and Enterococcus faecalis ATCC 33186 resulted in induction of hBD-2 mRNA. These results suggested that $H$. pylori (cag PAI) and other pathogens may induce hBD-2 mRNA expression via direct or indirect

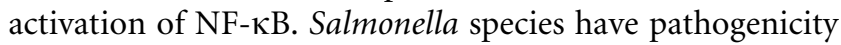



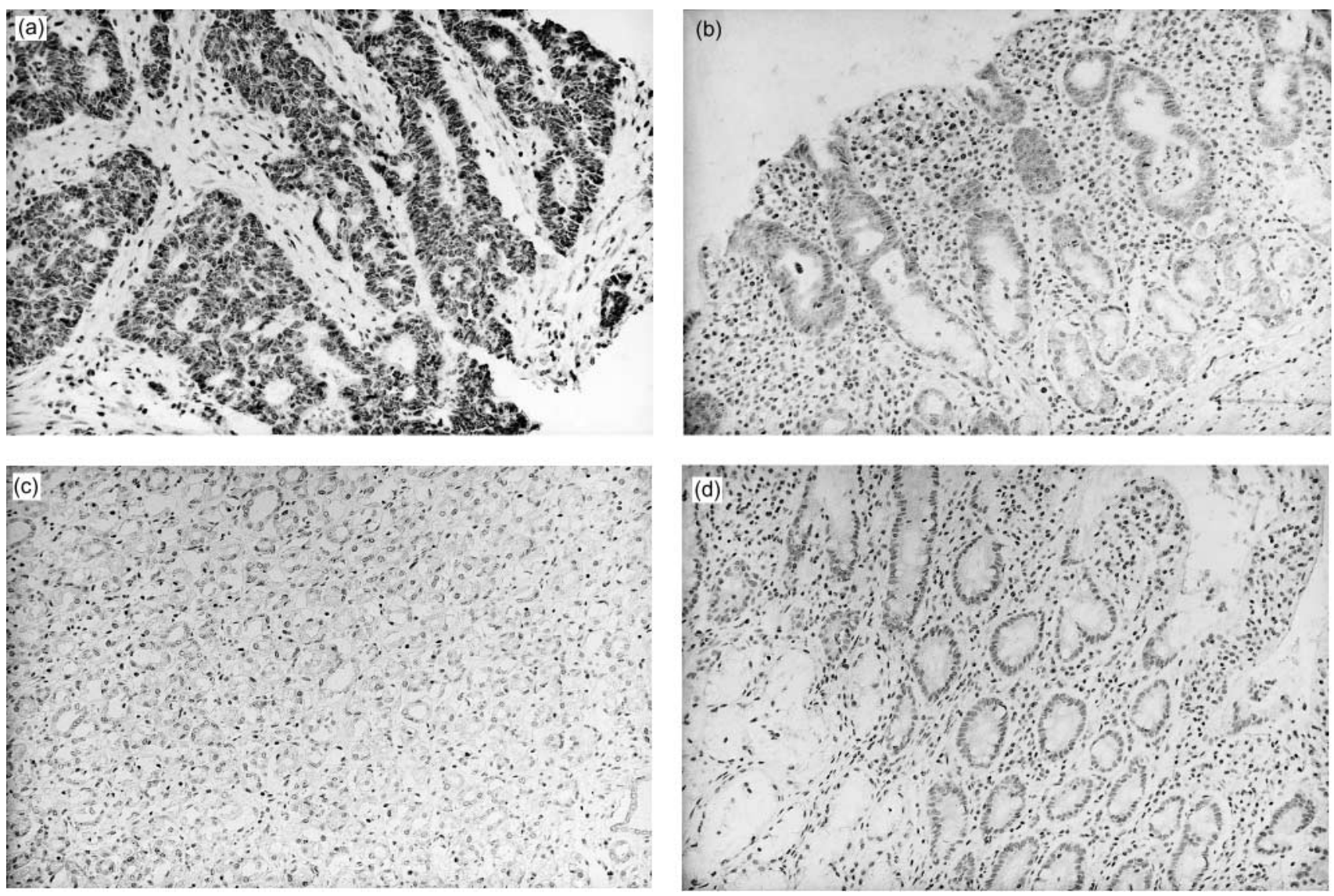

Fig. 5. hBD-2 protein expression in gastric cancer and paired adjacent tissue showing gastritis with or without $H$. pylori infection. Tissues were stained with anti-hBD-2 antibody. (a) and (b) Case 1: gastric cancer (moderately differentiated adenocarcinoma) and mucosa with gastritis with $H$. pylori infection. Positive staining was observed in gastric cancer cells in (a) and gastric epithelial cells in (b). (c) and (d) Case 2: gastric cancer (poorly differentiated adenocarcinoma) and mucosa with gastritis but without $H$. pylori infection. No positive staining was observed in (c) or (d). Magnification, $\times 120$.

islands (SPI 1 and 2) that may be important in induction of hBD mRNA expression. Pathogen-associated molecular patterns in these bacterial species and pattern-recognition receptors in MKN45 cells should be studied.

\section{Assessment of expression of hBD-2 in hBD-2-gene- transfected cells and antimicrobial effect of medium from transfected cells}

hBD-2 mRNA expression and secretion of hBD-2 protein into the culture medium were confirmed by the TaqMan RTPCR for hBD-2 described above and by immunoblot analysis using anti-hBD-2 polyclonal antibody (Fig. 6). A mouse embryonic fibroblast clone showing high production of hBD-2 protein, hBD-2-3T3J2-1, was selected for further study.

Culture supernatants from hBD-2-3T3J2-1 cells were used to evaluate the antimicrobial effect of overexpressed hBD-2 against $H$. pylori. Aliquots of $25 \mu \mathrm{l}\left(4 \times 10^{6}\right.$ c.f.u. $\left.\mathrm{ml}^{-1}\right)$ of $H$. pylori ATCC $43504^{\mathrm{T}}$ were cultured on HP agar for 3 days. The mean numbers of c.f.u. of $H$. pylori after $0,1,2$ and 4 h of pre-

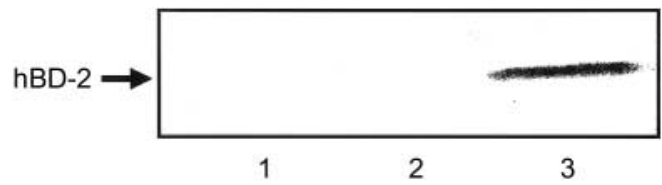

Fig. 6. Detection of hBD- 2 protein in culture medium of hBD-2 genetransfected 3T3J2 cells (lane 3), designated hBD-2-3T3J2-1, and parent 3T3J2 cells (lane 2) by immunoblot analysis using anti-hBD-2 antibody. Lane 1, RPMI 1640 medium control.

incubation with the culture supernatant (or with control medium) were respectively approximately $10^{5}\left(10^{5}\right), 0\left(10^{5}\right)$, $0\left(10^{5}\right)$ and $0(82)$. Thus, growth of $H$. pylori was inhibited completely after $1 \mathrm{~h}$ of incubation with the culture supernatant.

It has been reported that, at $10^{-5} \mathrm{M}$, chemically synthesized hBD-2 inhibits growth of $H$. pylori completely (Hamanaka et al., 2001). Schröder \& Harder (1999) reported that the $\mathrm{LD}_{90}$ 
values of natural hBD-2 preparations against Escherichia coli, Pseudomonas aeruginosa and Candida albicans were respectively 10,10 and $25 \mu \mathrm{g} \mathrm{ml}^{-1}$.

In the present study, we demonstrated that hBD-2-3T3J2-1 cells could secrete hBD- 2 protein into the culture medium and that this protein inhibited growth of $H$. pylori completely. In conclusion, hBD-2 originating from the epithelium clearly can be bactericidal for $H$. pylori, yet is elevated in infection. This suggests a role for hBD-2 in the pathophysiology of $H$. pylori infection that has yet to be defined.

\section{REFERENCES}

Diamond, G. \& Bevins, C. L. (1998). $\beta$-Defensins: endogenous antibiotics of the innate host defense response. Clin Immun Immunopathol 88, 221-225.

Hamanaka, Y., Nakashima, M., Wada, A. \& 7 other authors (2001). Expression of human $\beta$-defensin 2 (hBD-2) in Helicobacter pylori induced gastritis: antibacterial effect of hBD-2 against Helicobacter pylori. Gut 49, 481-487.

Harder, J., Bartels, J., Christophers, E. \& Schröder, J. M. (1997). A peptide antibiotic from human skin. Nature 387, 861.

Harder, J., Bartels, J., Christophers, E. \& Schröder, J. M. (2001). Isolation and characterization of human $\beta$-defensin-3, a novel human inducible peptide antibiotic. J Biol Chem 276, 5707-5713.

Isomoto, H., Mizuta, Y., Miyazaki, M. \& 7 other authors (2000). Implication of NF- $\mathrm{KB}$ in Helicobacter pylori-associated gastritis. Am J Gastroenterol 95, 2768-2776.
Japanese Research Society for Gastric Cancer (1995). Japanese Classification of Gastric Carcinoma, English edn. Tokyo: Kanehara.

Marshall, B. J., Warren, J. R., Francis, G. J., Langton, S. R., Goodwin, C.S. \& Blincow, E. D. (1987). Rapid urease test in the management of Campylobacter pyloridis-associated gastritis. Am J Gastroenterol 82, 200-210.

O'Neil, D. A., Cole, S. P., Martin-Porter, E., Housley, M. P., Liu, L., Ganz, T. \& Kagnoff, M. F. (2000). Regulation of human $\beta$-defensins by gastric epithelial cells in response to infection with Helicobacter pylori or stimulation with interleukin-1. Infect Immun 68, 5412-5415.

Schröder, J. M. \& Harder, J. (1999). Human $\beta$-defensin-2. Int J Biochem Cell Biol 31, 645-651.

Wada, A., Mori, N., Oishi, K. \& 10 other authors (1999). Induction of human $\beta$-defensin- 2 mRNA expression by Helicobacter pylori in human gastric cell line MKN45 cells on cag pathogenicity island. Biochem Biophys Res Commun 263, 770-774.

Wada, A., Ogushi, K., Kimura, T. \& 9 other authors (2001). Helicobacter pylori-mediated transcriptional regulation of the human $\beta$-defensin 2 gene requires NF-кB. Cell Microbiol 3, 115-123.

Yajima, T., Yagihashi, A., Kameshima, H., Kobayashi, D., Furuya, D., Hirata, K. \& Watanabe, N. (1998). Quantitative reverse transcriptionPCR assay of the RNA component of human telomerase using the TaqMan fluorogenic detection system. Clin Chem 44, 2441-2445.

Yoshida, Y. \& Hamada, H. (1997). Adenovirus-mediated inducible gene expression through tetracycline-controllable transactivator with nuclear localization signal. Biochem Biophys Res Commun 230, 426-430. 